\title{
Percepção de vida dos idosos portadores do HIV/AIDS atendidos em centro de referência estadual
}

Perception of life of elderly people living with HIV/AIDS served in center of reference

Allan Serra', Ana Hélia de Lima Sardinha², Amanda Namíbia Silva Pereira3, Silvia Cristina Viana Silva Lima $^{4}$

'Mestre em Saúde e Ambiente pela Universidade Federal do Maranhão (UFMA) - São Luís (MA), Brasil. Enfermeiro da Caixa de Assistência dos Funcionários do Banco do Brasil (CASSI-São Luís) - São Luís (MA), Brasil. allaserra@hotmail.com

Doutora em Educação pela Universidade Instituto Central em Ciências Pedagógicas, Cuba. Docente da Universidade Federal do Maranhão (UFMA) - São Luís (MA), Brasil. anahsardinha@ibest.com.br

${ }^{3}$ Mestranda pelo Programa de PósGraduação em Enfermagem da Universidade Federal do Maranhão (UFMA) - São Luís (MA), Brasil.

amanda_namibia@hotmail.com

${ }^{4}$ Doutora em Políticas Públicas pela Universidade Federal do Maranhão (UFMA) São Luís (MA), Brasil.

silvia.lima@aids.gov.br
RESUMO Este estudo analisou a percepção dos idosos com AIDS, atendidos em um centro de referência estadual do Maranhão. Trata-se de um estudo descritivo de abordagem qualitativa. Foram incluídos 46 idosos com AIDS, entrevistados no período de janeirojunho de 2010. Observou-se que quase não havia conhecimento sobre a doença antes de se contaminarem e que várias são as representações sobre a AIDS: "doença do outro"; "incurável"; "fatal", que pode levar à morte e ao preconceito. O diagnóstico positivo e a convivência com a AIDS são carregados e permeados de sentimentos negativos por parte do indivíduo portador e de sua família, havendo a necessidade de reestruturação da vida de cada um através do enfrentamento.

PALAVRAS CHAVE: Enfermagem; HIV; Síndrome de Imunodeficiência Adquirida; Idoso; Percepção.

\begin{abstract}
This study analyzed the perceptions of elderly people with AIDS cared for in a state reference center of Maranhão. This descriptive, qualitative study was conducted among 46 patients with AIDS, interviewed from January to June 2010. It was revealed that the patients very rarely had any prior knowledge of the disease before being infected and there are several representations of AIDS, "someone else's disease" "incurable", "fatal", which can lead to death and prejudice. The positive diagnosis and living with AIDS bring a host of negative feelings to the individual carrier and their family, requiring them to rebuild their lives through a process of facing up to the reality.
\end{abstract}

KEYWORDS: Nursing; HIV; Acquired Immunodeficiency Syndrome; Elderly; Perception. 


\section{Introdução}

De acordo com projeçóes estatísticas do ano de 2006, da Organização Mundial de Saúde (2006), há indícios de que o segmento da população idosa poderá ser responsável por quase $15 \%$ da população brasileira em 2020, com, aproximadamente, 30 milhóes de pessoas, o que fará do Brasil o $6^{\circ}$ país com o maior número de idosos do mundo.

No Brasil, um estudo conduzido por Moreira Júnior et al (2005), entre 2001 e 2002, acerca de atitudes e comportamentos sexuais entre homens e mulheres de 60 a 80 anos mostrou que $92,6 \%$ dos homens e $58,3 \%$ das mulheres referiram alguma atividade sexual no ano que precedeu a entrevista.

Diante dos dados, percebe-se que os idosos não estão excluídos da possibilidade de aquisiçẫo de doenças veiculadas pelo sexo. Vasconcelos, Alves e Moura (2001) explicam que uma significativa proporção de homens e mulheres permanece sexualmente ativa, pois a sexualidade, como interação física e íntima, tem comportamento vitalício e desenvolturas evolutivas que vão desde o nascimento até a morte.

Muitas são as causas atribuídas ao aumento dos índices de contaminação e de idosos vivendo com HIV/ AIDS: mudanças socioculturais, sobretudo na sexualidade; resistência por parte dos idosos em utilizar a camisinha; inovações na área da saúde; acesso à terapia antirretroviral; inovações na área medicamentosa; entre outras.

No aspecto social, o idoso convive com o estigma associado ao estar com AIDS, o medo de familiares e da comunidade; a diminuição dos recursos financeiros; questôes relacionadas à qualidade de vida, entre outras.

Azambuja (2010) considera um desafio diagnosticar pacientes soropositivos idosos por se tratar de mais um diagnóstico diferencial para um grupo já exposto a múltiplas patologias, o que leva à possibilidade de subnotificação de casos ou se reflete em diagnósticos tardios e em terapêuticas incorretas, acelerando a instalação de infecçôes oportunistas e de complicaçôes.

Feitoza, Sousa e Araújo (2004) salientam, ainda, que a dificuldade em diagnosticar a infecção pelo HIV/AIDS em indivíduos idosos deve-se ao número insuficiente de teste sorológico realizado por essa população. Assim, em consequência do diagnóstico tardio, tem-se encontrado a enfermidade em estágios avançados.

A AIDS, segundo Düttmann (2005), um objeto de reflexão filosófica de primeira ordem, explicita em todo o seu contexto aspectos subjetivos em alto grau de diversidade.

Assim, a interrogação que trazia acerca do assunto nos colocou diante de um fenômeno difícil de mensurar: retratar a percepção de vida dos idosos portadores do HIV/AIDS. O estudo em questâo torna-se importante à medida que resulta do mundo do percebedor, em que o paciente tem a possibilidade de deixar grafados os seus sentimentos como portador, trazendo-nos inquietações e reflexôes.

\section{Metodologia}

Trata-se de um estudo descritivo sobre a percepção de vida dos idosos portadores do HIV/AIDS, atendidos no Hospital Presidente Vargas, em São Luís - MA. Para compreender esses fenômenos vivenciados pelos portadores de HIV/AIDS, foi utilizada a metodologia qualitativa para compreender os significados buscados na experiência singular de cada indivíduo, utilizando a análise dos discursos dos sujeitos da pesquisa.

Foram incluídos neste estudo 46 idosos portadores do HIV/ AIDS, diagnosticados, com idade igual ou maior que 60 anos, em acompanhamento no Hospital Presidente Vargas, com capacidade cognitiva preservada, em uso ou não de medicamentos antirretrovirais, internados ou em acompanhamento ambulatorial, que aceitaram participar da pesquisa assinando, para tanto, o Termo de Consentimento Livre e Esclarecido.

Ressalta-se que a função cognitiva dos idosos foi avaliada através do Miniexame do Estado Mental. As entrevistas para coleta das informaçôes foram realizadas entre os meses de janeiro e junho de 2010.

As perguntas para coleta dos dados foram realizadas através de entrevista semiestruturada, entre os meses de janeiro e junho de 2010, contendo perguntas relacionadas a: conhecimento prévio que possuíam sobre 
HIV/AIDS, impacto da notícia do diagnóstico positivo e convivência com HIV/AIDS.

Os referenciais da bioética, preconizados na Resolução nº 196/96, do Conselho Nacional de Saúde (CNS), foram considerados neste estudo. De acordo com parecer substanciado do Comitê de Ética em Pesquisa em Seres Humanos do Hospital Universitário Presidente Dutra, o Projeto no 232/09 foi aprovado em 08/01/2010.

\section{Resultados}

A população da pesquisa foi composta, predominantemente, por idosos de 60 a 65 anos (57\%); solteiros (63\%); naturais de Pinheiro (40\%); do sexo masculino (61\%); pardos (52\%); católicos (80\%); que moram em casa alugada (91\%), do tipo alvenaria (83\%), com até 2 filhos (50\%); aposentados (78\%), com nível de escolaridade até o ensino fundamental $(50 \%)$ e renda média de um salário mínimo (52\%).

Os depoimentos obtidos no estudo permitem compreender os objetivos desta investigação de acordo com os resultados e a discussão de análise qualitativa, conforme se verá a seguir.

\section{O Significado da Aids para Idosos Soropositivos}

Quando questionados sobre o conhecimento prévio que possuíam sobre HIV/AIDS, os idosos entrevistados apresentaram respostas que variaram de nenhum a algum conhecimento a respeito da doença. Alguns informaram que nada sabiam sobre AIDS antes de se infectarem ou que, quando existia informação, essa era muito escassa e superficial.

Nada. Não sei praticamente nada. (Sujeito 06).

Eu não tinha nenhum conhecimento. O problema foi esse [...] Se fosse no dia de hoje, eu garanto para você que eu não pegaria essa doença. Porque eu sei como é que é, eu sei o problema tudo [...]. Agora, nuns tempos atrás, a gente quase não tinha informação [...] Então eu garanto: se fosse hoje, eu não entrava nessa [...]. (Sujeito 03).

Por outro lado, alguns deles relataram ter tido informaçóes e possuir alguma ideia acerca do que era AIDS. Todavia, observou-se nos depoimentos abaixo que parece haver uma distinção entre 'ouvir falar' e ter informaçóes corretas sobre a doença.

Muito pouco se falava desse negócio de AIDS. Não sabia tanto quanto eu sei hoje [...] Às vezes, a gente ouvia alguém falar, né? "Oh, a AIDS" ou "fulano tá com AIDS".

A gente não tinha noção do que era AIDS. Ouvia só falar. Como outra qualquer. Mas não tinha informação. (Sujeito 05).

Sempre ouvi falar no rádio, mas não era tão explicativa que nem hoje. A gente não tinha tanta informação. [...] Logo que surgiu essa doença aí, eu já ouvi falar. [...] mas não tinha ideia nenhuma de como era. (Sujeito 07).

$\mathrm{Na}$ fala dos entrevistados, a AIDS é vista como 'doença do outro', uma coisa abstrata, a crença no 'ver para crer'.

Punuxa vida! Já tinha ido a diversas palestras [...] Veio gente de fora, vieram falando, falando, explicando como era, como náo era [...] Distribuiu camisinha e aquelas coisa toda. [...] Meio que a gente náo sente. [...] "Ah, isso não é nada disso, não, tal". Eu não acreditava! Porque quando não toca na gente, a gente não acredita, cê me entendeu? [...] Depois é que a gente vai ver [...] $\mathrm{Na}$ hora que a coisa aperta. (Sujeito 01).

Tinha, mas nunca tinha visto uma pessoa com isso aí. Você entendeu como é que é o negócio. 
Acho que o mal da gente é isso ai. [...] Se eu visse, não entrava nisso aí. [...] Você escuta falar e não vê, quer dizer, é que nem diz o outro: "só vendo para crer" (risos). Mas, quando fui ver, já tinha me lascado. (Sujeito 02).

Sim. Mas nunca passou pela minha cabeça que um dia isso ia acontecer comigo. [...] Nunca. (Sujeito 04).

A representação que a AIDS tem para os entrevistados é de uma doença incurável, fatal, que pode levar à morte, e ainda impregnada de muita discriminação e preconceito, mas que pode ser controlada, dominada.

Eu achava, achava não, ela mata. Se a pessoa não se cuidar, ela mata. (Sujeito 02).

[...] Porque fala "ah, é uma doença que não tem retorno. Você pegou esta doença, acabou". De fato, não acabou, não acaba. Mas derruba a pessoa, assim, mentalmente. [...] Você náo consegue se concentrar. (Sujeito 03).

Porque você sabe que é uma doença que não tem cura. Não tem cura. Perigoso. [...] Antigamente, eu morria de medo disso dai. Nossa! Isso dai era uma coisa! Hoje, vamos supor, tem gente que é muito discriminado. [...] Eu vou olhar para trás, é uma doença como outras, que mata também. (Sujeito 04).

Bom, agora, com o pouco que eu sei, eu acho que é uma doença como outra qualquer... É só você se cuidar. [...] É triste? É. Você tem cura? Não tem. Mas você, sabendo levar, se controlar, você vive bem, sossegado. [...] O preconceito atrapalha um pouco, porque a gente percebe que [...] quando a pessoa sabe, fica meio te olhando de lado, então é com isso ai que a gente fica magoado [...]. (Sujeito 05).

\section{A Descoberta da Aids para Idosos Soropositivos}

A descoberta da condição de soropositivo para o HIV ocorreu, quase sempre, em função do surgimento de alguns sintomas/adoecimento, estando a decisão de submeter-se ao teste de HIV a cargo de pedidos médicos, não aparecendo como uma atitude própria do sujeito.

Eu fui ao médico, ele pediu um exame, aí constatou [...]. E foi onde minha vida mudou tudo [...]. Se transformou num pesadelo para mim. (Sujeito 03).

Depois de ir a vários médicos, um resolveu me pedir o exame para HIV, foi ai que descobriu tudo. Sofri muito antes de descobrir o que eu tinha, pois passava muito mal e me internei algumas vezes. (Sujeito 06).

Nota-se que a primeira reação, na maioria dos entrevistados, pode ser um estado temporário de choque, e, quando termina essa sensação de torpor, aparece a negação, revelada na maioria dos entrevistados.

A minha reação quando eu soube do resultado? A minha reação não foi nenhuma, nenhuma [...]. A minha mulher sentiu, porque ela tava no dia comigo [...]. Mas eu não me abalei, porque não adiantava mais nada, né? Eu tinha que ter evitado antes [...]. Mas eu não sinto nada. Eu fui no médico buscar os outros resultados de anemia, essas coiseras, sabe? O doutor falou "e ai $A$. você baqueou?". Eu falei "Não, normal. Agora tem que tocar o barco para frente porque, se eu baquear, pior para mim" [...]. (Sujeito 02).

Eu não acredito que eu tenho. Tenho. Que tenho, tenho. Mas eu não acredito. Não sinto nada, nada, nada. (Sujeito 04).

Além da negação, a racionalização se apresenta como um importante mecanismo de defesa, podendo 
auxiliar na sobrevivência e na manutenção de uma estrutura egoísta, permitindo ao indivíduo processar e elaborar a sua nova condição de vida.

Então, eu procuro viver, não lembrar essas coisa na cabeça, entendeu? [...] Olha, eu vou falar uma coisa para você, o que eu ponho na minha cabeça é que tem coisa pior. Eu fui vítima, fui. Eu prejudiquei minha esposa, eu que tirei a vida dela [...]. É duro demais, mas tem pior. Tem sempre que pensar nisso: tem pior. (Sujeito 04).

Desde que descobri que estava doente, procuro me conscientizar que agora não tem mais jeito. Tenho que viver minha vida nessa nova condição. (Sujeito 05).

Os idosos entrevistados relataram, também, que, ao receberem o diagnóstico, apresentaram múltiplos sentimentos: amargura, tristeza, desespero, solidão, pânico, incredulidade, como transparece nos depoimentos abaixo.

Olha, meu filho, eu chorei dia e noite quando o médico me falou. Ele falou, eu chorei, chorei, sentimental mesmo. Não esperava isso [...]. Falei “meu Deus do céu! Por que Deus não me deu o caminho para eu ver o que foi, para náo pegar isso aî?" [...]. Mas não teve jeito, né? [...] (Sujeito 01).

Já tinha parado e aí voltou. Eu comecei a menstruar, aí eu via, eu ia no médico e o médico dava remédio, passava, tudo bem [...]. E ai me saiu umas feridas na boca. Ai vai no médico, farmácia, remédio, tudo [...]. Nada valia. Ai um médico disse para mim: "vamos fazer o exame de HIV porque isso dai é todo o sintoma do HIV". [...] Ai, eu já sai dali desorientada. Fui fazer, veio o papel: positivo. E eu fiquei desesperada, louquinha, louquinha. Ai tornou a fazer outro exame: positivo. [...] Foi muito difícil. Porque en falava que não poderia ter acontecido isso comigo... Porque eu não fui uma pessoa má. O que eu fiz pros outros? Não poderia ter acontecido isso comigo. Eu fiquei em pânico. (Sujeito 05).

Ah, Deus me livre! [...] Não foi fácil, não [...]. Eu fiquei doida! Vixi! [...] Eu falei "nossa, pelo amor de Deus!". É duro. [...]. A gente fica desesperada, né [...]. Não é fácil, não. Eu pensei "eu vou morrer." (Sujeito 06).

A gente se sente acanhado. Nessa idade aqui e ter isso ai [...]. Se Deus me levasse, eu ficaria até mais contente [...]. (Sujeito 07).

O impacto da notícia do diagnóstico positivo e a convivência com HIV/AIDS, às vezes, é carregado e permeado de sentimentos tão intensos e angustiantes que o desejo de morte se faz presente.

E por aí vai [...]. Vou vivendo enganado, tô me enganando a eu mesmo [...]. Tem vez que eu penso em me jogar embaixo de um caminhão [...].(Sujeito 01).

Então, a vida da gente é desse jeito [...] a gente tem que [...] eu tô levando uma vida, até que, razoavelmente, não é das piores, não. Tem hora que dá [...] aqueles pensamentos [...]. Então você fica meio desorientado. [...] Eu já tive em situação pior. Eu já tentei até dar um tiro na cabeça e tudo. Foi logo no começo. (Sujeito 03).

A culpa é outro sentimento que surge com grande destaque nos discursos dos entrevistados, sendo vivenciada sobre diferentes vertentes. Estas são intimamente associadas às histórias de vida de cada um dos idosos estudados, especialmente no que diz respeito às relaçóes de gênero, à forma de contágio e de conhecimento da soropositividade.

Primeiramente, destaca-se o fato de que a convivência com o sentimento de culpa aparece como um tormento, uma perturbação, acarretando desconforto. 
Eu penso em tantas coisas: "porque eu fiz isso! Porque eu fui fazer? Porque eu não presto, eu fui o culpado [...]. Eu vou embora! Eu vou sumir!". E é assim, eu penso nessas coisas. Como é que eu vou tirar isso da cabeça? Não tem jeito. [...] Como é que eu faço? Então, é só chorar, chorar, chorar (suspiro). Fazer o quê?? [...] (Sujeito 01).

Ah, você não consegue concentrar nas coisas boas, é difícil [...]. A gente não consegue, parece que tá sempre com aquela culpa, aquele peso na cabeça, que você aprontou, você fez isso, fez aquilo, então [...]. (Sujeito 03).

Reconhecer-se responsável pela própria condição de portador do HIV parece agravar o sentimento de culpa.

Se eu fosse de uma mulher só, ia falar que era dela [...], mas não foi, cê entendeu? [...] Então, fiquei sem saida. Fica sem saida. Vou te culpar você, que você náo tem culpa? Culpar a Maria, que não tem culpa? Não posso! Fiquei assim [...]. (Sujeito 01).

Mas é difícil conseguir viver [...] Porque eu, como eu, o professor, nós sempre falava assim: "não tem que se julgar culpado". Mas eu me sinto culpado, ué. Porque culpado fui eu de ter pegado a doença; eu saí procurando [...] Então, eu não vou culpar outra pessoa. A culpa tem que ser em cima de mim mesmo, então [...] você não tem como melhorar. (Sujeito 03).

Alguns depoimentos evidenciam uma tentativa de amenização do sentimento de culpa. Recorrem à identidade, à condição de trabalhador/provedor e de macho como alternativa para justificar a infecçâo e suavizar a vivência de culpa.

Quer dizer: eu fui uma vitima também. Só que, de vítima, fiz vitima [...]. Então, por isso, embora eu perdi minha esposa [...], mas eu tenho a consciência tranquila, porque eu sempre fui um bom pai, me sacrifiquei, batalhei muito, dei tudo para eles, dei condiçóes que eu não tive. Eu sou um cara que trabalhei desde os sete anos de idade [...]. (Sujeito 04).

Não tinha ideia nenhuma de como era, porque o meu negócio era corrido. Eu fazia essa linha de Imperatriz, chegava aqui na segunda-feira, carregava, voltava para Imperatriz, descarregava de novo e assim ia a semana toda [...]. Não tinha tempo para ouvir rádio, ver tevê [...]. Eu tinha quatro filhos para criar, educar. Então, tinha de trabalhar, ir lá e voltar e trazer dinheiro. (Sujeito 07).

\section{A Reação da Família do Idoso Soropositivo Com a Descoberta}

Os depoimentos abaixo tratam da reação da família com sentimentos antagônicos - primeiramente, rejeição e, depois, aceitação.

Ah, quando ficou sabendo, cortou relação, né? Comigo. E, graças a Deus, não pegou. [...] Meus filhos, quando ficaram sabendo [...], minha mulher, os dois [...] me mandaram embora de casa. Eu falei: "Eu vou embora, sim [...]". [...] Ai meu filho mais velho falou: "pai, não vai fazer besteira, não. Isso é coisa da vida, isso é coisa que acontece. Fica quietinho aí". Ai a mulher falou; "Fica aí, não tem problema, não [...] Só que você para mim acabou”. Falei: "tudo bem", eu aceitei. Aceitei, porque eu tava errado. Eu tô errado. Aí eu aceitei. (Sujeito 01)

Ai eu falei para minha filha, minha filh a ficou meio desorientada também, mas ela se acostumou. Hoje, ela me ajuda com muita coisa, falando comigo. E tem o meu filho do meio, que ele também não apavorou [...]. Ele fica meio assustado, com medo das coisas, porque não tem orientação [...]. Ficou meio com medo das 
coisa, por exemplo, talheres, copos, essas coisas, coisas de casa [...]. Até que, enfim, ele caiu em si, foi ouvindo eu acho que alguma [...], a televisão explicando alguma coisa, ai ele parou de ficar meio assustado. E o caçula, até hoje, não falou nesse assunto comigo. Eu falei para a muIher dele e ela falou para ele, e ele náo aceitou e não aceita. [...] E não falou comigo, e até hoje não puxou assunto. (Sujeito 05).

Minha mulher chorava o dia inteiro. Dia e noite [...]. Chorava [...]. (Sujeito 07).

\section{O Enfrentamento do Idoso Soropositivo na Sociedade}

No que diz respeito à convivência com a AIDS e em como enfrenta o fato de estar com a doença, a maioria dos entrevistados prefere manter o resultado em sigilo, tendo, quase que exclusivamente, como único confidente a família nuclear - esposa e filhos.

Então, eu procuro não deixar ninguém saber, não [...]. E só eu, vocês aqui (referindo-se aos profissionais do hospital) e lá em casa. [...]. Agora, aonde eu tô trabalhando, ninguém sabe, porque se souber dá o fim na gente lá, então [...]. (Sujeito 02).

Porque bem pouca gente sabe do meu problema [...]. A situação minha é minha esposa, meus dois filhos, uma nora sabe, a outra não sabe. Só se contaram para ela e eu náo tô sabendo. E minha irmã. Por parte da minha esposa, ninguém sabe. (Sujeito 03).

De lá para cá, a gente, meus filhos sabem. Acho que minha irmã não sabe. Tem o meu irmão mais novo que não sabe, mas a maioria sabe [...]. E ela (namorada), da última vez que nós fomos, ela chegou e comentou, e eu falei para ela: "aconteceu comigo". Mas ela não falou mais nada. Só que, mesmo assim, eu não fico contente, eu gostaria de discutir o problema [...]. É, eu gostaria, né? Não sei [...]. Ela não fala nada. Sabe, mas en gostaria de discutir esse problema, só que [...] toda vez que vai "Oh, póe camisinha". Ela fala "póe camisinha". Quer dizer, ela exige mesmo. Então quer dizer que ela tá sabendo mesmo e sabe o risco. (Sujeito 04).

\section{O Tratamento da Aids para os Idosos Soropositivos}

Tendo em vista o caráter incurável da AIDS, o tratamento passa a ser visto como um recurso indispensável à sobrevivência. $\mathrm{O}$ uso de medicamentos e as mudanças de hábitos de vida são inseridos no dia a dia dos entrevistados, no sentido de alcançar uma melhor qualidade de vida. Assim, o tratamento e o autocuidado tornamse meios de enfrentamento da doença.

Então, a minha saúde é boa, tá tudo controlado. Eu tomo os remédios tudo direitinho, sabe? Quer dizer que eu acho que [...] eu vou tocando a vida desse jeito aí até [...]. [...] Eu achava, achava não, ela mata. Se a pessoa não se cuidar, ela mata [...]. Eu me alimento bem, sabe? Eu não bebo [...]. Mas se você não se cuidar, ela mata mesmo [...]. (Sujeito 02).

O que eu posso dizer, que com a minha idade que eu tô hoje, com sessenta e três anos, e com essa doença, até que eu tô indo longe demais. Porque eu tento, eu forço as coisas [...]. Então, eu evito das coisas. [...]. Eu procuro melhorar, no sentido, assim, procurar me alimentar, tomar meus remédios certo, tudo, não tomar bebida alcoólica, não fazer extravagância, para ver se a gente vai dando mais uns passos. (Sujeito 03).

Antes disso, tomava uma cerveja, uma pinga, tomava um vinho [...]. Agora já não. De quatro anos para cá, só tomo refrigerante. "Assim cê atura", assim fala o médico, "assim, cê vai 
longe". Como na hora certa, descanso bastante, isso aí vale muito. [...]. (Sujeito 01).

Eu não tomo cerveja com álcool. Depois que eu comecei com o medicamento, parei. [...]. A única coisa que eu me preocupo é se um dia eles não fornecer mais esse medicamento, porque ele tá indo tão bem que eu tenho medo de ficar sem ele. Então, eu me preocupo, não deixo faltar, porque eu acho importante. Depende do tratamento a qualidade de vida. (Sujeito 04).

É, mudou, né? [...] Como eu disse para você, eu era baileira, né? Eu só não ia na segunda porque não tinha (risos), mas [...]. Eu larguei de ir ao baile, larguei de sair à noite para náo tomar friagem, para não tomar um chuvisqueiro [...]. Já tenho bastante idade, né? Agora, se eu não me cuidar um pouco [...]. E vivendo, eu tô vivendo bem, né? Não ligo porque eu tenho AIDS, eu só me cuido. Eu só me cuido, não faço extravagância [...]. [...] eu nunca mais tomei chuva, larguei de fumar, larguei de beber, porque eu bebia, né? Viajava [...]. Larguei tudo isso [...], procurando manter mais um pouco a minha saúde. (Sujeito 05).

No entanto, para alguns deles, parece não ter havido mudanças drásticas no estilo de vida. A condição de soropositivo é incorporada como mais um aspecto a ser vivenciado, não interferindo no modo de vida anterior ao diagnóstico.

Não, não mudou nada. [...]. Eu continuo trabalhando. E eu trabalho de um jeito que, se botar um menino no meu lugar, não faz o que eu faço. Tenho certeza que não. Se for preciso, eu pego peso [...]. Comigo não tem esse negócio de nhenhenhe, não. [...]. (Sujeito 02).

O fato de estar doente náo afetou em nada meu dia a dia. Continuo fazendo tudo igualzinho antes. Não me sinto, de forma alguma, como uma incapacitada ou como doente (Sujeito 05).
Apesar dos medos e dificuldades de convivência com alguns fatores estressores do dia a dia e da própria doença, o desejo de viver e de aproveitar a vida ainda são preservados, originando sentimentos de esperança.

Mas que, para mim, eu acho que existe gente em pior situação do que eu. Então, é isso aí que eu procuro alimentar [...]. Uma esperança, $e$ viver com essa esperança. (Sujeito 02).

Eu tô querendo aproveitar o que eu posso. $O$ que eu posso eu tô querendo aproveitar, o máximo que eu puder. (Sujeito 03).

Então, é assim [...]. O resto eu vou forçando para levar a minha vida bem. Porque não adianta, agora, chorar pelo leite derramado [...]. Tem que lutar, né? Enquanto tá vivo, tem que lutar [...]. (Sujeito 05).

\section{Discussão}

Atualmente, grande parte do conhecimento chega à população de forma rápida e correta, porém, décadas atrás, a difusão do conhecimento não era assim. Falar de sexo e sexualidade era um assunto, praticamente, proibido. Nesse sentido, a falta de conhecimento caracteriza-se como problema.

Apesar dos idosos deste estudo afirmarem possuir informação/conhecimento sobre a doença, pôdese constatar que não haviam percebido estar sob risco antes de se infectarem. O risco é uma combinaçẫo de fatores. Essa combinação de fatores geralmente é, em parte, a identificação de uma ameaça. Em outra parte, a identificação de uma vulnerabilidade.

Ayres et al (2010) dizem que as condiçóes que afetam a vulnerabilidade individual são de ordem cognitiva (informação, consciência do problema e das formas de enfrentá-lo), comportamentais (interesse e habilidade para transformar atitudes e ações a partir daqueles elementos cognitivos) e sociais (acesso a recursos e poder para adotar comportamentos protetores). 
Nesse contexto, como se pode perceber nos depoimentos dos entrevistados, apenas informaçôes sobre formas de transmissão e situaçóes de risco podem ser insuficientes para a adoção de comportamentos protetores. Não basta informação, pois estar informado não significa, necessariamente, conhecer; estar ciente não significa, necessariamente, tomar medidas; decidir tomar medidas não significa, necessariamente, fazer.

Todavia, Peruga e Celentano (2003) lembram que, apesar de se ter ciência de que, no caso da AIDS, o grau de informação que um indivíduo possui sobre formas de transmissão e situaçóes de risco não é suficiente para que passe a adotar um comportamento protetor, a falta de informaçóes básicas contribui para aumentar sua vulnerabilidade.

Com relação à categoria 'A descoberta da AIDS para idosos soropositivos', Ferreira (2002) aborda, em seu trabalho sobre violência aos direitos humanos entre indivíduos portadores do HIV/AIDS, que não é de se surpreender que, diante do diagnóstico para a soropositividade, diversas reaçóes e comportamentos dos sujeitos possam surgir, como, por exemplo, medo da doença, vivências de culpas ou medos relacionados às respostas sociais.

Receber o diagnóstico soropositivo para o HIV acarreta, num primeiro momento, grande impacto, despertando reaçóes e sentimentos desestruturantes e acionando mecanismos de defesa, a fim de fazer frente aos medos e angústias decorrentes do saber-se contaminado. Torna-se importante ressaltar que, apesar do espaço de tempo decorrido entre o momento da recepção do diagnóstico positivo para HIV e a data das entrevistas, os relatos ainda estavam carregados de emoção.

Sentimentos contraditórios, indiferença e descrédito são comumente evocados. A negação (ou, pelo menos, a negação parcial) é usada por quase todos os entrevistados nos primeiros estágios da doença ou logo após a constatação, e, ainda, em alguns casos, numa fase posterior.

A negação é explicada, por Kübler-Ross (1998), como um para-choque, depois de notícias inesperadas e chocantes, deixando que o sujeito se recupere com o tempo, mobilizando outras medidas menos radicais. Comumente, a negação é uma defesa temporária, sendo, logo, substituída por uma aceitação parcial.

Estando a AIDS atrelada à ideia de fatalidade/ morte, Figueiredo (2005) fala que essa se torna primordial para a incorporação da nova condição de soropositivo para o HIV, a forma como é dado o diagnóstico para o indivíduo.

Sendo assim, dependendo de como se diz e do tempo de que o indivíduo dispóe para conscientizar-se e assimilar a notícia de sua nova história de vida, torna-se capaz de desprender-se de mecanismos de defesa mais radicais, como a negação, para, enfim, fazer uso dos mais brandos.

$\mathrm{Na}$ categoria 'A reação da família do idoso soropositivo com a descoberta', percebe-se que o diagnóstico positivo para HIV traz reações não apenas ao indivíduo portador, mas também a sua família. Os membros da família experimentam diferentes estágios de adaptação que, em certa medida, assemelham-se aos do portador do HIV.

Nesse contexto de doença, Souza (2009) explica que cada família movimenta-se de forma singular, interpretando a situação a partir de uma percepção em que sua cultura, seus códigos e suas regras influenciam seu comportamento e o processo de comunicação entre seus membros.

Quanto à categoria ' $\mathrm{O}$ enfrentamento do idoso soropositivo na sociedade', Goffman (2008) define estigma como um atributo que é profundamente depreciativo e que, aos olhos da sociedade, serve para desacreditar a pessoa que o possui. $\mathrm{O}$ autor argumenta que o indivíduo estigmatizado é visto como uma pessoa que possui uma 'diferença indesejável'. Observa, também, que o estigma é atribuído pela sociedade com base no que constitui diferença ou desvio, e que é aplicado pela sociedade por meio de regras e sançóes que resultam no que ele descreve como um tipo de identidade deteriorada para a pessoa em questão, originando discriminação e preconceito.

Dessa forma, pode-se dizer que a AIDS tem 'duas dores': a dor da própria enfermidade e a dor dos olhos dos outros. Assim, o medo da rejeição, principalmente no ambiente de trabalho, e o sofrimento causado pelo 
preconceito e pela possibilidade de discriminação afetam de forma contundente os sujeitos desta amostra.

Sobre a categoria 'O tratamento da AIDS para o idoso soropositivo', Parker (2000) explica que, no início da década de 1980, no Brasil, a AIDS trouxe à tona, de maneira nova e assustadora, os fantasmas construídos no imaginário social sobre sexualidade e morte, sobre o desfiguramento e o enfraquecimento físico, sobre a vulnerabilidade e o risco visto na cara do outro. Mais do que qualquer outra doença da era moderna, a AIDS revelou nossa relação ainda não resolvida com a diferença e os diferentes, relembrando-nos da longa história que sempre vinculou o medo da diferença com a discriminação, o estigma e o preconceito.

Nemes (2000) observou que a história dos pacientes que aderiram ao tratamento medicamentoso é uma história de superação de dificuldades relacionadas, sobretudo, à adaptação da medicação ao estilo de vida e às questôes vinculadas ao estigma da doença.

\section{Conclusão}

$\mathrm{Na}$ fala dos entrevistados, percebeu-se que estes não possuíam nenhum ou quase nenhum conhecimento sobre a AIDS antes de adoecerem. Todavia, observou-se que havia uma distinção entre 'ouvir falar' e ter informaçôes corretas sobre a doença. Muitos não haviam percebido estar sob risco, caracterizando, assim, vulnerabilidade.

São várias suas representaçôes sobre a AIDS: 'doença incurável", 'fatal', que pode levar à morte e impregnada de discriminação e preconceito. Diante do diagnóstico para soropositividade, há uma mistura de sentimentos, como: medo, indiferença, descrédito, negação, amargura, tristeza, desespero, solidão e pânico. Em alguns casos, o impacto desse diagnóstico e a convivência com o HIV/AIDS são carregados de sentimentos negativos, onde o desejo de morte se faz presente.
Percebeu-se, claramente, que o diagnóstico positivo para HIV traz reaçōes não apenas ao indivíduo portador, mas também à sua família. Os membros da família experimentam diferentes estágios de adaptaçâo que, em certa medida, assemelham-se aos do portador do HIV.

A manutenção do casamento, nos indivíduos casados, sofreu algumas alteraçóes, especialmente no contexto sexual, havendo a recusa de um contato mais íntimo por parte do (a) companheiro (a), ou, então, uma negativa por decisão própria do portador do vírus.

O aumento dos índices de contaminação pelo HIV em idosos pode estar associado a vários fatores, entre eles: contexto sociocultural, sobretudo na área da sexualidade; mudanças demográficas que apontam para o envelhecimento populacional; inovaçóes na área da saúde; falha nos esforços de prevenção para com esse segmento; as vulnerabilidades individual, social, programática e outras.

A Política Nacional do Idoso, instituída pela Lei no 8.842/94, foi considerada um marco na construção de açôes voltadas para a atenção à saúde do idoso, como também a criação dos Conselhos Estaduais do Idoso e, posteriormente, o Estatuto do Idoso. Constata-se, então, a importância de políticas que garantam o direito a não discriminação desses idosos, especialmente para esse grupo que enfrenta sentimentos de abandono e vergonha, constrangimento, medo e sensação de ser tratado de forma (in) diferente.

Com o presente estudo, percebeu-se, portanto, a importância de se pesquisar sobre a sexualidade em idosos, permitindo atravessar as barreiras dos mitos e os tabus que esse grupo enfrenta. Isso possibilitará uma maior conscientização acerca do HIV/ AIDS, além de lhes permitir sentirem-se aceitos na sociedade. 


\section{Referências}

AYRES JR, C.M et al. AIDS, Vulnerabilidade e Prevenção. Disponível em: <http://www.aidscongress.net/7 congresso>. Acesso em: 19 mar. 2010.

AZAMBUJA, K.F. Perfil do Paciente HIV+ com mais de 60 anos no Estado do Rio de Janeiro. Disponível em: <http://www. aidscongress.net/7 congresso>. Acesso em: 28 fev. 2010.

DÜTTMANN, A.G. La discórdia del SIDA: cómo se piensa y se habla acerca de um vírus. Madri: Anaya \& Mario Muchnik, 2005.

FEITOZA, A.R.; SOUZA, R.S.; ARAÚJO, M.F.M. A magnitude da infecção pelo HIV/AIDS em maiores de 50 anos no município de Fortaleza- CE. Jornal Brasileiro de Doenças Sexualmente Transmissíveis, Rio de Janeiro, v.16, n. 4, p. 32-37, 2004.

FERREIRA, A.B.H. Novo Aurélio século XXI: o dicionário da língua portuguesa. 3 ed. Rio de Janeiro: Nova Fronteira, 2002.

FIGUEIREDO, W. Assistência à saúde dos homens. Ciência e Saúde Coletiva, Rio de Janeiro, v.10, n.1, p. 105-109, 2005.

GOFFMAN, E. Estigma: notas sobre a manipulação da identidade deteriorada. Rio de Janeiro: Guanabara, 2008.

KÜBLER-ROSS, E. Sobre a morte e o morrer. São Paulo: Martins Fontes, 1998.

MOREIRA JÚNIOR, E.D. et al. Prevalence of sexual problems and related help-seeking behaviors among mature adults in Brazil: data from the Global Study of Sexual Attitudes and Behaviors. São Paulo Medical Journal, São Paulo,v. 123, n.5, p. 234-241, 2005.

NEMES, M. I. B (org). Avaliação da aderência ao tratamento por antirretrovirais em usuários de ambulatórios do sistema público de assistência à AIDS no Estado de São Paulo. Brasília, DF: Coordenação Nacional DST/AIDS; Ministério da Saúde, 2000. (Série Avaliação, n.1). Disponível em: <http://www.Aids.gov.br/avalia1/home. htm>. Acesso em 28 fev. 2010:

ORGANIZAÇÃO MUNDIAL DE SAÚDE. Envelhecimento ativo: uma política de saúde. Brasília: Organização Pan-Americana de Saúde, 2005. Disponível em: <http://www.unati.uerj.br>. Acesso em: 27 mar. 2010.

PERUGA, A.; CELENTANO, D.D. Correlates of AIDS knowledge in samples of the general population. Social Science \& Medicine, Philadelphia,v.46, n.7, p.16-19, 2003.

SOUZA, C. Sexualidade na terceira idade. Disponível em: <http:// www.soropositivo. org/arquivo-de-noticias/4233-a-sexualidadena-terceira-idade.html>. Acesso em 22 jun. 2010.

VASCONCELOS, E.M.R.; ALVES, F.A.P.; MOURA, L.M.L. Perfil epidemiológico dos clientes HIV/AIDS na terceira idade. Revista Brasileira Enfermagem, Brasília, v.54, n.3, p. 435-445, 2001.

Recebido para publicação em Novembro/2012

Versão final em Abril/2013

Conflito de interesse: não houve

Suporte financeiro: inexistente 